\title{
Shopping for Health: Fruit ${ }^{1}$
}

\author{
Ashley R. Kendall and Wendy J. Dahl ${ }^{2}$
}

Fruits taste good, and they are good for you. Some fruits are very nutrient dense. This means they contain lots of the vitamins, minerals, antioxidants, and fiber that your body needs to stay healthy. Whether you like fresh fruit or fruit juice, frozen fruit or fruit from a can, it's important to choose a variety of different fruits every day. Here are some tips to help you before, during, and after your fruit shopping trip.

\section{Shopping Tip Before Shopping}

If your grocery list just states "fruit," you may not be fully prepared to shop for fruit. A little more planning ahead can make your fruit shopping easier, faster, and less expensive. The easiest way to start your fruit shopping is by looking at your local grocery store's weekly specials, which often can be found in the newspaper or online. These specials list which fruits are on sale. Buying fruit on sale saves you money.

It's also helpful to know when certain fresh fruits are in season. Although you can buy most fresh fruits year-round, seasonal fruits tend to be priced lower and have the best taste. Visit http://www.sustainabletable.org/shop/seasonal to find seasonal fruits in Florida.

Now that you know which fruits are on sale and which fruits are in season, the last step is to make your list. A complete fruit shopping list will help you remember all the fruits you need to buy and help you make the most out of what's on sale.

\section{While Shopping Fresh Fruit}

Look for the grocery store's specials on fresh fruit, but don't buy fruit just because it's on special. Consider carefully your likes and dislikes, and consider how much fruit you are likely to eat. Fresh fruit has a short shelf life and is not a bargain if it ends up spoiling.

Prepackaged, ready-to-eat fresh fruit is a quick and easy way to eat more fruit. This fruit is already washed and sliced and can be eaten as a quick snack. The downside to buying fruit this way is that it tends to be more expensive.

Try fresh fruit shopping at your local farmers' market. The farmers' market is a great place to find seasonal, farm-fresh,

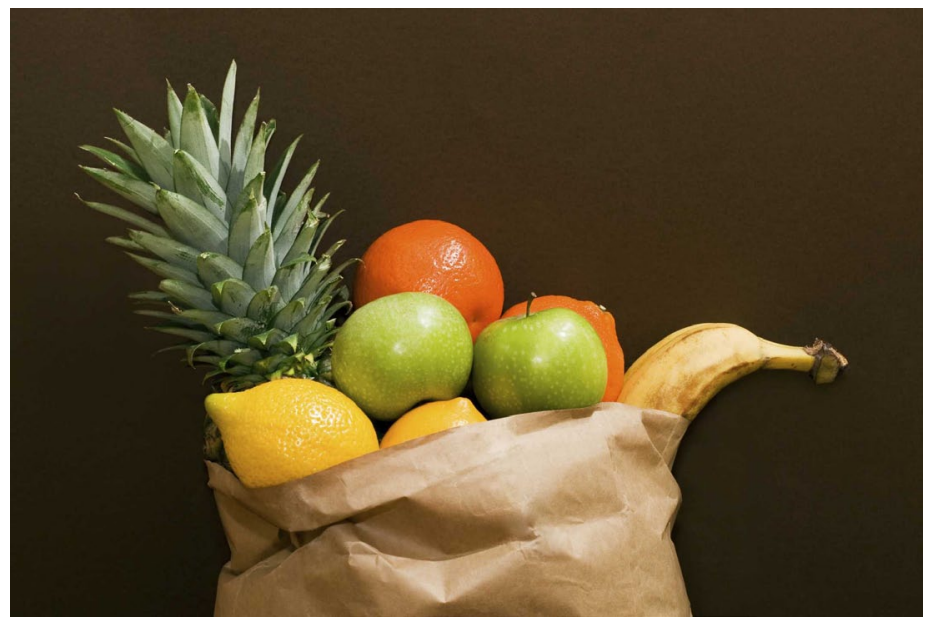

1. This document is FSHN12-20, one of a series of the Food Science and Human Nutrition Department, Florida Cooperative Extension Service, Institute of Food and Agricultural Sciences, University of Florida. Original publication date March 2013. Visit the EDIS website at http://edis.ifas.ufl.edu.

2. Ashley R. Kendall and Wendy Dahl, assistant professor, Food Science and Human Nutrition Department, Florida Cooperative Extension Service, Institute of Food and Agricultural Sciences, University of Florida, Gainesville, FL 32611. 
locally grown fruit. Visit http://apps.ams.usda.gov/FarmersMarkets to find a farmers' market near you.

\section{Frozen and Canned Fruit}

Frozen and canned fruits tend to cost less and have a long shelf life. When you see these items on sale, stock up on them. Frozen and canned fruits tend to have the same flavor and nutrients as they did when they were fresh. This is because they were frozen or canned within a few hours of harvest. Canned fruits may be packaged in syrup, which adds more sugar to the fruit. Look for fruits that are canned in $100 \%$ fruit juice or water.

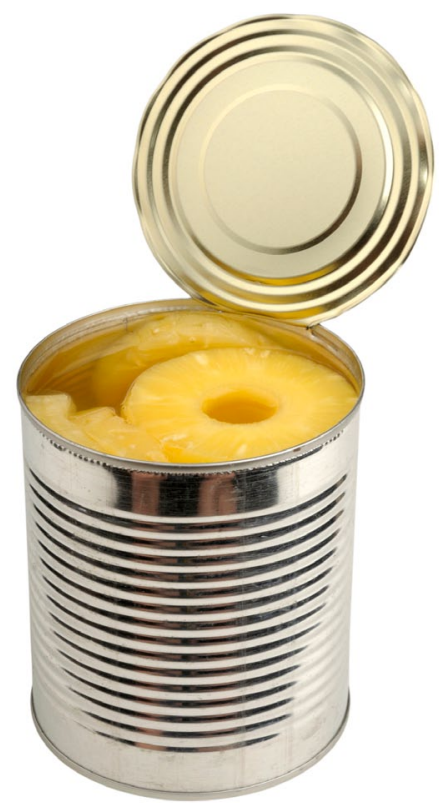

\section{Dried Fruit}

Dried fruit is ready to eat and makes a quick snack or tasty addition to a salad. A $1 / 4$-cup serving of dried fruit is about the same as eating $1 / 2$ cup of fresh fruit. Dried fruit has a long shelf life, so stock up when it's on sale.

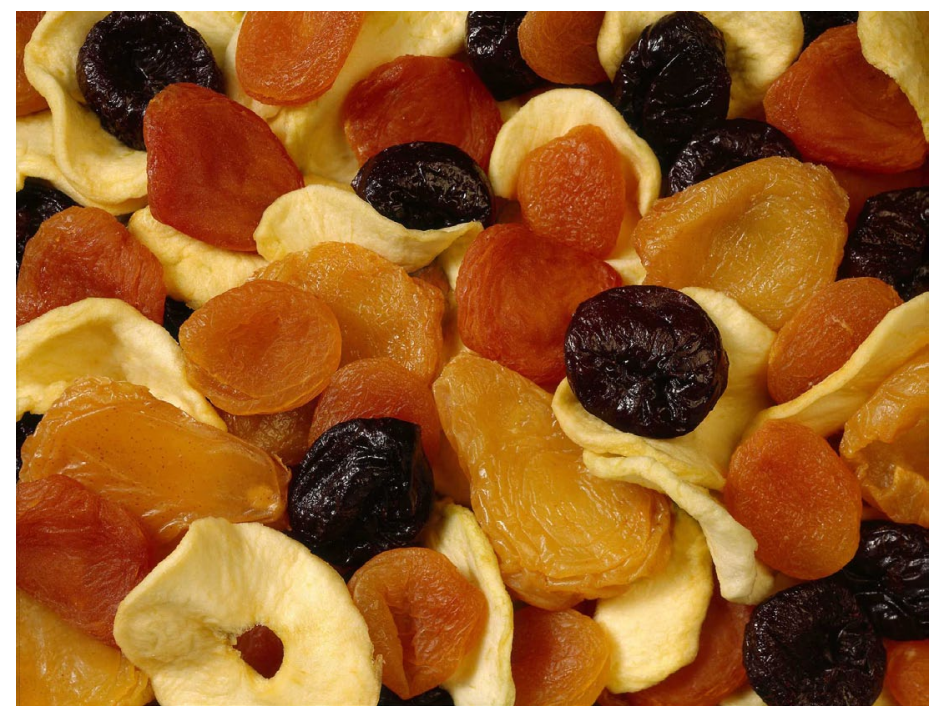

\section{Fruit Juice}

Drinking fruit juice is another way to add fruit to your diet. Be sure to buy $100 \%$ fruit juice instead of fruit drinks. Fruit drinks often have a lot of added sugar and little real juice. Most fruit juice contains little to no fiber, so choose fresh, canned, or frozen fruit to maximize your fiber intake.

\section{After Shopping}

Now that you have finished your fruit shopping, it's important to know how to properly store your fruit. Proper storage extends fruit freshness. Visit http://www.fruitsandveggiesmorematters.org/?page_id=165 to learn more about how to store different fruits.

It is best to eat fresh fruit within days after purchasing to prevent it from spoiling. Throwing away spoiled fruit costs you money. Canned, frozen, or dried fruit can always be on hand if you run low on fresh fruit.

Freezing fruit is an option if you have extra fresh fruit. Some fruits freeze better than others. Learn how to properly freeze fruit by referring to Preserving Food: Freezing Fruits (http://edis.ifas.ufl.edu/fy720).

\section{Handling Fresh Fruit Safely}

In addition to proper storage, it's important to handle fresh fruit safely during preparation and consumption. It is important to first wash hands thoroughly with warm water and soap. Next, make sure that all cutting boards and utensils are clean and sanitized. Designating a cutting board and utensils specifically for fresh produce is the best option. You should avoid using a cutting board on which raw meat, poultry, or seafood has been prepared. Once fresh produce is cut, it should be refrigerated or consumed immediately. If left at room temperature for more than two hours, cut fresh fruit should be discarded.

For most canned fruits, there is no preparation. However, once opened, canned fruits should be refrigerated or consumed immediately. An open can of fruit left at room temperature should be discarded within a few hours.

Frozen fruits should be kept frozen until ready to use. Once frozen fruit is thawed, it should not be refrozen and should be treated like fresh fruit.

Dried fruit has a much longer shelf life and may be left at room temperature for an extended period (days or weeks). Because dried fruit is relatively low in moisture, there is less chance of spoilage or food-borne illness. However, an 
open package of dried fruit should be placed in a sealed container and refrigerated if it is to be stored indefinitely.

For more information about how to properly prepare and handle fruits, see Fresh Cut Produce: Safe Handling Practices for Consumers (http://edis.ifas.ufl.edu/fy484).

In addition to general guidelines for handling fresh fruit, there are more specific guidelines that pertain to particular fruits, including pome/stone fruits, citrus, and berries.

\section{Apples, Pears, Peaches, Nectarines, Plums}

- Wash fruit with cool water

- Remove peel to lessen contamination

- Remove bruised/damaged areas by cutting

- For cored fruits, remove core prior to cutting

For more information, see Pome and Stone Fruits: Safe Handling Practices for Consumers (http://edis.ifas.ufl.edu/ FY486).

\section{Orange, Lemon, Lime, Grapefruit}

- Wash fruit with cool water, even if removing rind, but especially if using rind

- Scrub rind with a brush intended for produce

- Discard peel

- Remove damaged areas by cutting
For more information, see Citrus: Safe Handling Practices for Consumers (http://edis.ifas.ufl.edu/fy483)

\section{Berries, Grapes, Kiwi}

- Wash in cool water

- Remove and discard bruised/damaged fruit

- Remove and discard any leaves or stems

For more information, see Berries and Small Fruits: Safe Handling Practices for Consumers (http://edis.ifas.ufl.edu/ fy485).

\section{Choose Variety}

In addition to commonly consumed fruits, there are many more fruits to try. These include everything from dried fruits other than prunes and raisins to interesting tropical fruits (Table 1).

\section{Recommended Websites}

For more information about fruit, refer to the following websites:

www.choosemyplate.gov

www.fruitsandveggiesmorematters.org

\section{References}

The Cook's Thesaurus. (n.d.) http://www.foodsubs.com. Accessed November 19, 2012.

Table 1. Unique fruits, sensory qualities, and usual form of consumption

\begin{tabular}{|l|l|l|}
\hline Fruit & Sensory characteristics & Availability \\
\hline Star fruit & Sweet, sour flavor; crisp texture & Fresh \\
\hline Coconut & Sweet, nutty, chewy (fresh), chewy-crisp (dried) & Fresh, dried \\
\hline Guava & Sweet, tropical & Fresh, juice \\
\hline Kumquat & Intense flavor, citrusy, juicy & Fresh \\
\hline Lychee & Sweet, juicy, texture similar to grape & Fresh, canned \\
\hline Mango & Sweet, juicy, pulpy (when fresh), chewy (if dried) & Fresh, frozen, juice, dried \\
\hline Papaya & Subtle tropical and sweet flavor, soft texture & Fresh, canned, dried \\
\hline Pomegranate & Tart, sweet flavor; crunchy, pulpy (fresh) texture & Fresh, juice \\
\hline Passion fruit & Tart, tropical & Fresh, juice \\
\hline Dried apple & Subtle sweet, chewy & Dried \\
\hline Dried berries & Very sweet, chewy & Dried \\
\hline Dried figs & Sweet, chewy & Dried \\
\hline Dates & Very sweet, chewy & Dried \\
\hline (Source: The Cook's Thesaurus, n.d.) & \\
\hline
\end{tabular}

